\title{
Do the $\mathrm{O}_{2}$ Schumann-Runge Bands Participate in keV Collision-Induced Dissociation Experiments?
}

\author{
Yawei Lin, Paul M. Mayer \\ Department of Chemistry, University of Ottawa, 10 Marie-Curie, Ottawa, ON, Canada K1N 6N5
}

\begin{abstract}
In high-energy (keV) CID experiments, oxygen has the unique ability to enhance specific ion fragmentation pathways that lie within a relatively narrow band of activation energy. It has been previously proposed that this oxygen-enhanced dissociation phenomenon is due to the participation of the $\mathrm{O}_{2} \mathrm{~B}^{3} \Sigma_{\mathrm{u}}{ }^{+}-\mathrm{X}^{3} \Sigma_{\mathrm{g}}{ }^{-}$(Schumann-Runge) system in the collision complex. During the collision, oxygen is first excited to its $\mathrm{B}^{3} \Sigma_{\mathrm{u}}{ }^{+}$state before it returns this energy to the projectile ion. This energy drives the nonstatistical dissociation of the projectile provided there is an energetically accessible pathway in resonance with the absorbed radiation. To probe the validity of this hypothesis, a modified VG-ZAB mass spectrometer was used to observe the photon emissions from $\mathrm{keV}$ collisions of a selection of projectile ions with $\mathrm{O}_{2}$ target gas. By studying the resulting collision-induced emission (CIE) spectra, a second potential mechanism came to light, one that involves the near-isoenergetic $\mathrm{O}_{2}^{+} \cdot \mathrm{A}^{2} \Pi_{\mathrm{u}} \rightarrow \mathrm{X}^{2} \Pi_{\mathrm{g}}$ state transition.
\end{abstract}

Key words: Collision-induced dissociation, Collision-induced emission, Oxygen target gas, Charge transfer excitation, Schumann-Runge band system, Oxygen ion emission band system

\section{Introduction}

n mass spectrometry, ion dissociation may occur either
spontaneously (metastable ion) or due to (intentionally
supplied) additional activation. Such activation is typically
achieved through collisions with neutral target gases, a
process called collision-induced dissociation (CID). In a
magnetic sector mass spectrometer, CID mass spectra are
obtained by colliding mass-selected ions that have keV lab
frame energies with a stationary target gas. During the keV
ion-target collision, part of the translational energy of the
projectile ion can be converted into internal energy, and this
internal energy is assumed to be redistributed statistically

Electronic supplementary material The online version of this article (doi:10.1007/s13361-010-0011-x) contains supplementary material, which is available to authorized users.

Correspondence to: Paul M. Mayer; e-mail: pmmayer@uottawa.ca among the internal degrees of freedom, in the form of vibrational energy in the ground state, prior to dissociation $[1,2]$. In this assumption, the CID mass spectra resulting from the various competing dissociation pathways are independent of how the ion obtained its internal energy in the first step.

Various target gases can be used to obtain CID mass spectra, such as $\mathrm{N}_{2}$, Ar and He. According to empirical observations, the CID mass spectra attained using different target gases are quite similar [3]. However, $\mathrm{O}_{2}$ behaves differently from most target gases in that it can significantly favor some specific fragmentation reactions. This nonergodic behavior of $\mathrm{O}_{2}$ has aroused the interest of several groups. Flammang et al. reported a series of $\mathrm{O}_{2}$-enhanced dissociations in CID mass spectra and compared them with those of other common target gases, such as $\mathrm{N}_{2}$ and $\operatorname{Ar}$ [48]. Holmes et al. $[9,10]$ performed a systematic study of $\mathrm{O}_{2}$ enhanced dissociations, including the loss of $\mathrm{CH}_{3}$. from $\mathrm{CH}_{3} \mathrm{CH}^{+} \mathrm{X}\left(\mathrm{X}=\mathrm{OH}, \mathrm{NH}_{2}, \mathrm{SH}, \mathrm{CH}_{3}\right)$, the loss of $\mathrm{CH}_{3}$. and 
Cl. from $\mathrm{CH}_{3} \mathrm{C}^{+}(\mathrm{Cl}) \mathrm{CH}$, the loss of $\mathrm{C}_{2} \mathrm{H}_{5}$. from $\mathrm{CH}_{3} \mathrm{CH}_{2} \mathrm{CH}^{+} \mathrm{X}$ ( $\mathrm{X}=\mathrm{OH}$ and $\mathrm{NH}_{2}$ ), the loss of $\mathrm{H}$. from ${ }^{+} \mathrm{CH}_{2} \mathrm{OH}$ and ${ }^{+} \mathrm{CH}_{2} \mathrm{NH}_{2}$, and the loss of $\mathrm{O}$ from 1,2-, 1,3- and $1,4-\mathrm{C}_{6} \mathrm{H}_{4}\left(\mathrm{NO}_{2}\right)_{2}{ }^{+}$, etc. They found that these dissociation reactions share some common features in that they are all high-energy simple bond cleavage reactions. Moreover, their minimum energy requirements all fall within a relatively narrow energy range $\left(450-565 \mathrm{~kJ} \mathrm{~mol}^{-1}\right)$. Some examples are shown in Figure 1. In the ${ }^{+} \mathrm{CH}_{2} \mathrm{OH}$ CID mass spectrum, the peak with $\mathrm{m} / \mathrm{z} 30$ (fragment ion from the loss of $\mathrm{H}$. from ${ }^{+} \mathrm{CH}_{2} \mathrm{OH}$ ) is more intense when $\mathrm{O}_{2}$ is used as the target gas rather than $\mathrm{He}$, indicating that $\mathrm{H}$. loss from ${ }^{+} \mathrm{CH}_{2} \mathrm{OH}$ is an $\mathrm{O}_{2}$-enhanced dissociation. The ${ }^{+} \mathrm{CH}_{2} \mathrm{NH}_{2}$ CID mass spectrum shows the same pattern. The reaction leading to $\mathrm{O}$ loss from the nitromethane cation, $\mathrm{CH}_{3} \mathrm{NO}_{2}{ }^{+}$. (which produces a peak with $\mathrm{m} / \mathrm{z} 45$ ), does not thermochemically fall within the above energy window $(229 \mathrm{~kJ} /$ mol), but enhancement is still observed. Note that the fragment ion peak exhibits significant broadening due to the release of kinetic energy during the dissociation, an indication that this channel involves a large reverse-energy barrier. The authors speculated that though the reaction energy, $\Delta H$, is $229 \mathrm{~kJ} \mathrm{~mol}^{-1}$, the real energy requirement for this fragmentation could still fall within the $450-565 \mathrm{~kJ} \mathrm{~mol}^{-1}$ energy range [10]. To rationalize these observations, the specific energy range of the dissociation was correlated to a property of the $\mathrm{O}_{2}$ target itself. It has been reported [16] that the $\mathrm{B}^{3} \Sigma_{\mathrm{u}}{ }^{+}$state of $\mathrm{O}_{2}$ has a long lifetime (in the range of milliseconds), and also that its potential energy relative to the $\mathrm{X}^{3} \Sigma_{\mathrm{g}}{ }^{-}$ground state is $598-682 \mathrm{~kJ} / \mathrm{mol}$ (the latter being the dissociation limit of $\mathrm{O}_{2}$ to $\mathrm{O}\left({ }^{3} \mathrm{P}\right)$ to $\mathrm{O}\left({ }^{1} \mathrm{D}\right)$, as shown in Figure 2), which is close to the $\mathrm{O}_{2}$-enhancement dissociation energy window. Accordingly, it was proposed [10] that $\mathrm{O}_{2}$ was excited from the ground $\mathrm{X}^{3} \Sigma_{\mathrm{g}}{ }^{-}$state to the $\mathrm{B}^{3} \Sigma_{\mathrm{u}}{ }^{+}$state (belonging to the $\mathrm{B}^{3} \Sigma_{\mathrm{u}}{ }^{+}-\mathrm{X}^{3} \Sigma_{\mathrm{g}}{ }^{-}$Schumann-Runge system), and that this $\mathrm{B}$ state of $\mathrm{O}_{2}$ resonantly transfers this energy quantum back to the projectile ion in the collision complex, allowing the ion to undergo dissociations with activation energies that lie within that range.

Although the hypothesis explained the experimental results very well, there has been no concrete experimental evidence for the formation of the $\mathrm{O}_{2}$ B state during the collision. It is known that when excited states of a species are produced during the collision process, some of them will transit to lower states, emitting characteristic photons with specific wavelengths when they do so (collision-induced emission, CIE). In this study, CIE spectra were obtained for different ion- $\mathrm{O}_{2}$ collisions in order to probe the excited electronic states produced, especially the $\mathrm{O}_{2} \mathrm{~B}^{3} \Sigma_{\mathrm{u}}{ }^{+} \rightarrow$ $\mathrm{X}^{3} \Sigma_{\mathrm{g}}{ }^{-} \mathrm{SR}$ emission band (the only observed emission associated with the $\mathrm{B}^{3} \Sigma_{\mathrm{u}}{ }^{+}$state [16]).

\section{Experimental Procedures}

All experiments were performed on a modified VG ZAB mass spectrometer. The original, double-focusing mass spectrometer [11-13] was employed with an added third field-free region (3FFR), as previously described [14, 15]. Ions were generated with $80-90 \mathrm{eV}$ electron ionization in the ion source of the instrument. The ions were transmitted to the 3FFR, where they collided with the target gas in the collision cell at a collision gas pressure that reduced the precell ion flux by $10 \%$ or $40 \%$ as needed.

A spectrograph (Acton SpectraPro 275, $27.5 \mathrm{~cm}$ focal length, $1200 \mathrm{~g} \mathrm{~mm}^{-1}$ holographic grating; Acton Research Corp, Acton, MA, USA) and a thermoelectrically cooled charge-coupled device (CCD) detector (Andor DV401-UV, front-illuminated with UV coating; Andor Technology, Belfast, UK) were installed above the collision cell to detect photons emitted due to ion-target collisions [15]. Emissions from the excited state species were observed directly with the CCD detector cooled to a temperature of $-35{ }^{\circ} \mathrm{C}$. The

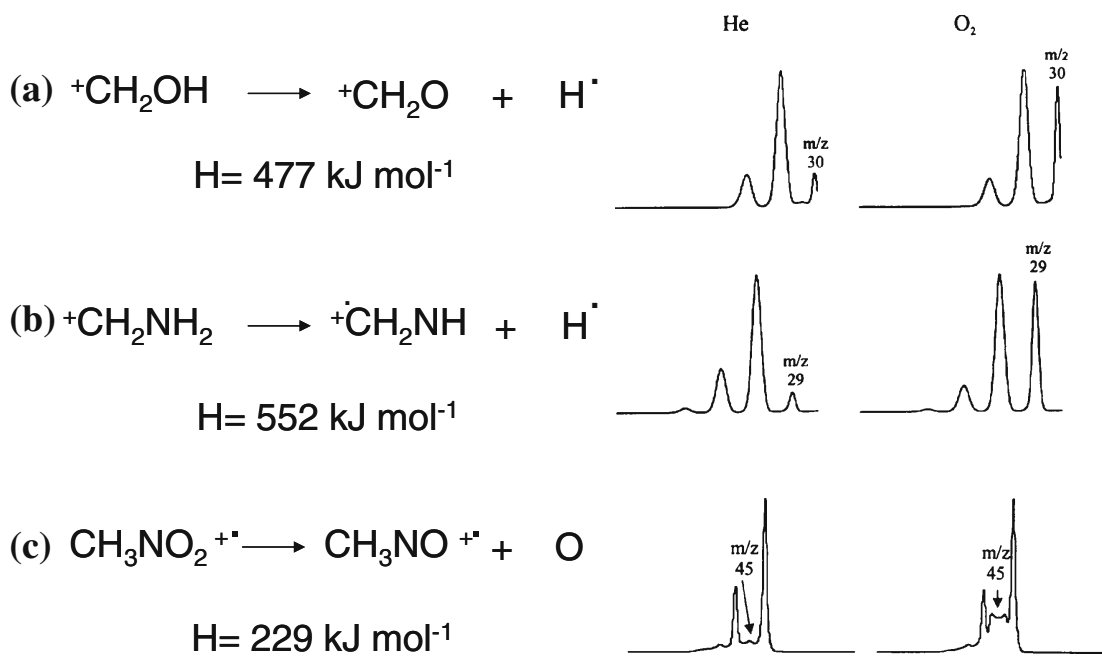

Figure 1. Partial $\mathrm{He}$ and $\mathrm{O}_{2} \mathrm{CID}$ mass spectra of (a) source ${ }^{+} \mathrm{CH}_{2} \mathrm{OH}$, (b) source ${ }^{+} \mathrm{CH}_{2} \mathrm{NH}_{2}$, and (c) $\mathrm{CH}_{3} \mathrm{NO}_{2}{ }^{+}$, from Holmes et al. [10]. Republished with permission from Aubry, C., Holmes, J.L.: The behavior of oxygen as a collision-induced dissociation target gas. J Am. Soc. Mass Spectrom. 12(1), 23-29 (2000) 


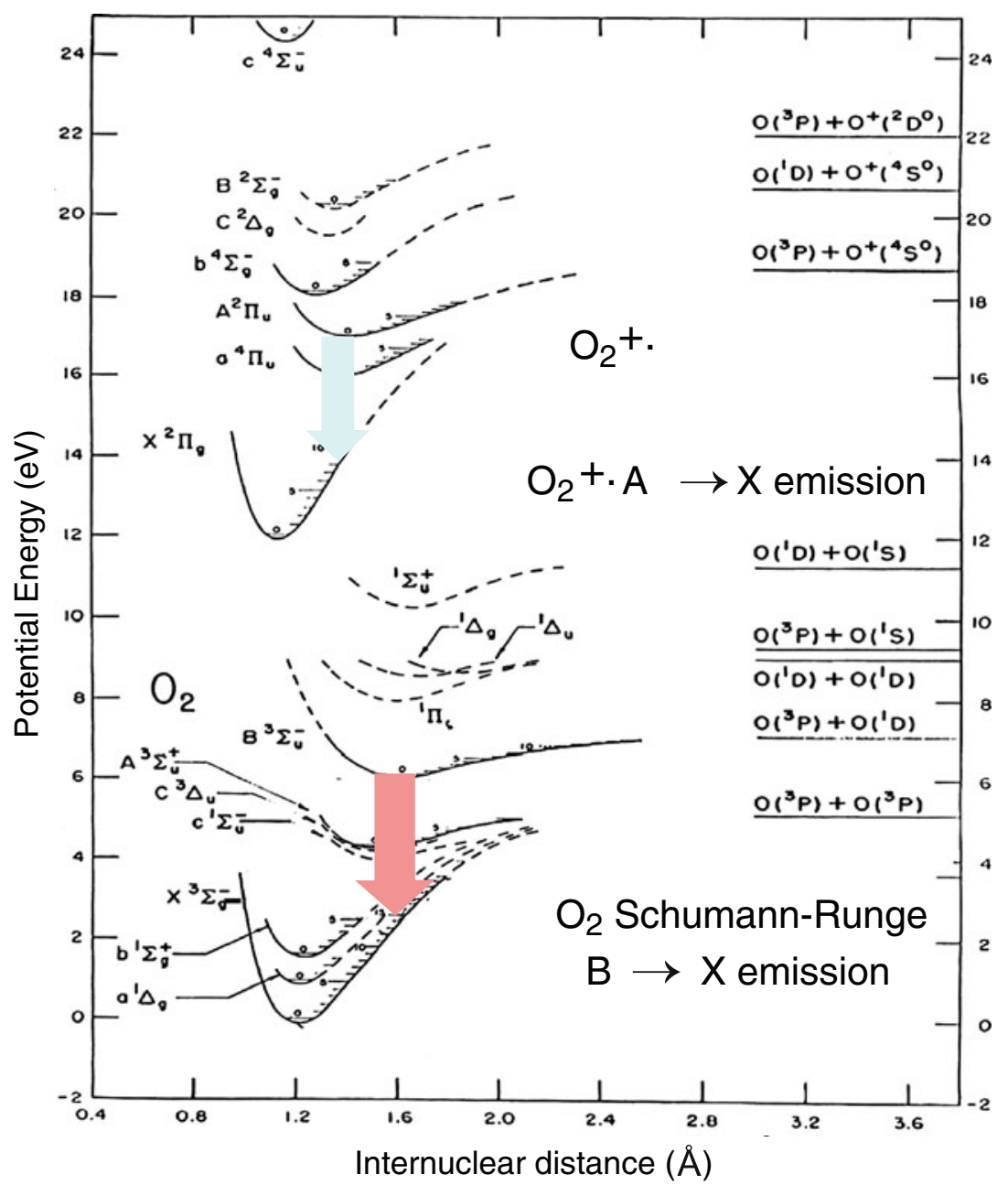

Figure 2. Potential energy diagram of $\mathrm{O}_{2}$ and $\mathrm{O}_{2}{ }^{+\cdot}$ from Krupenie [16]. Republished with permission from Krupenie, P.H.: Spectrum of molecular oxygen. J. Phys. Chem. Ref. Data. 1(2), 423-534 (1972)

entrance slit of the spectrograph was set to $3.0 \mathrm{~mm}$, providing a spectral resolution of $8.5 \mathrm{~nm}$ (measured at full width at half-height for atomic lines). Optical emissions were recorded from 190 to $1020 \mathrm{~nm}$ using the Andor MCD 2.63.1.8 program and recorded in 14 separate segments, each of which was $50-70 \mathrm{~nm}$ wide. The data were accumulated in two periods, ranging from $1 \mathrm{~h}$ to $4 \mathrm{~h}$, at an ion translational energy of $8 \mathrm{keV}$ for each segment in full vertical binning reading mode. Each segment had the background subtracted, and background spectra were collected prior to signal acquisition under exactly the same conditions except without an ion beam. Spectral spikes resulting from cosmic rays were removed digitally by the program. Horizontal binning was performed manually in the ASCII file by combining the data from every 20 pixel columns, and the overlapping portion of the spectrum at the two ends of each window was averaged.

Higher-resolution spectra were obtained by reducing the entrance slit width to 1.0 or $0.5 \mathrm{~mm}$, resulting in a spectral resolution of 3.0 or $2.4 \mathrm{~nm}$, and the data acquisition time of each segment was increased to 8 or $10 \mathrm{~h}$. Throughout the accumulation period, the ion flux intensity was monitored and adjusted to ensure that it remained stable, and each segment was normalized to the flux intensity of the ion beam.

\section{Results and Discussion}

The Schumann-Runge (SR) system $\left(\mathrm{B}^{3} \Sigma_{\mathrm{u}}{ }^{+} \rightarrow \mathrm{X}^{3} \Sigma_{\mathrm{g}}{ }^{-}\right)$is the most extensively studied system of $\mathrm{O}_{2}$; more than a hundred lines of this system have been identified. The emission bands range from 207 to $535 \mathrm{~nm}$, are red-degraded, and show no prominent band heads. Most other $\mathrm{O}_{2}$ transitions are considerably weaker than the $\mathrm{B}^{3} \Sigma_{\mathrm{u}}{ }^{+} \rightarrow$ $\mathrm{X}^{3} \Sigma_{\mathrm{g}}{ }^{-}$system, as they are forbidden by electric dipole selection rules.

The $\mathrm{CH}_{3} \mathrm{NO}_{2}{ }^{+}$. target system was studied as $\mathrm{CH}_{3} \mathrm{NO}_{2}{ }^{+}$. ions can undergo $\mathrm{O}_{2}$-enhanced dissociation, as mentioned in the "Introduction." In the experiment, $\mathrm{CH}_{3} \mathrm{NO}_{2}{ }^{+}$ion beams were prepared and sufficient target gas was supplied to achieve a $10 \%$ reduction in the beam (i.e., essentially singlecollision conditions [11]). The resulting CIE spectra were obtained after two hours of accumulating signals for each section. Figure 3a shows the CIE spectra obtained from 
(a)

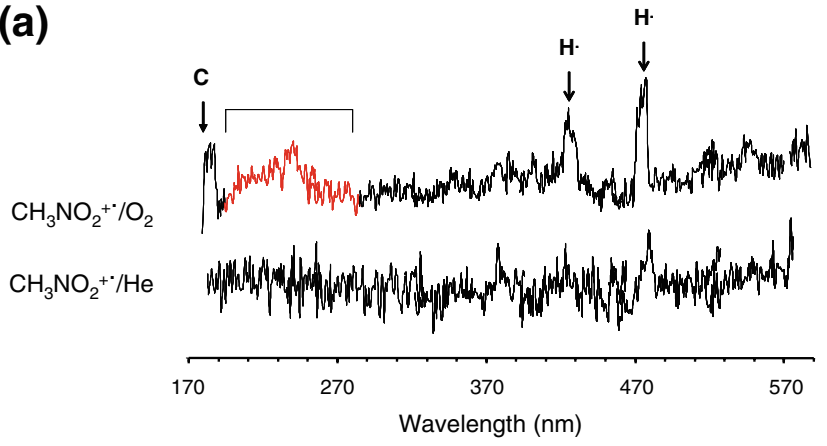

(b)

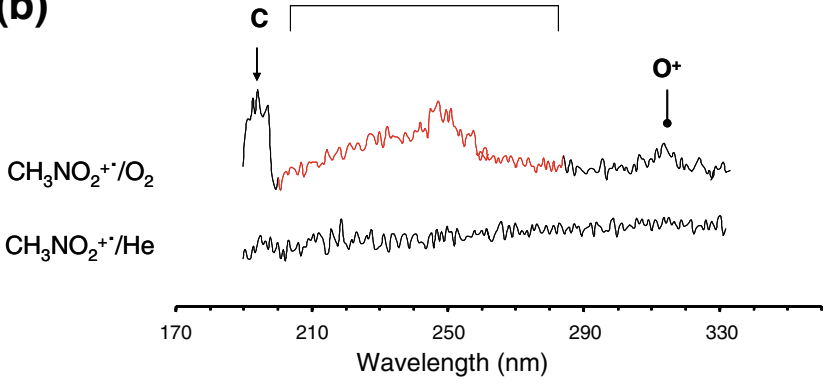

Figure 3. (a) $\mathrm{CIE}$ spectra of $\mathrm{CH}_{3} \mathrm{NO}_{2}^{+} / \mathrm{O}_{2}$ and $\mathrm{CH}_{3} \mathrm{NO}_{2}{ }^{+} / \mathrm{He}$ : $10 \%$ beam reduction, slit width $3 \mathrm{~mm}$; accumulation time $1 \mathrm{~h}$. (b) CIE spectra of $\mathrm{CH}_{3} \mathrm{NO}_{2}^{+} / \mathrm{O}_{2}$ and $\mathrm{CH}_{3} \mathrm{NO}_{2}{ }^{+} / \mathrm{He}$ : $40 \%$ beam reduction, slit width $3 \mathrm{~mm}$; accumulation time $2 \mathrm{~h}$

$\mathrm{CH}_{3} \mathrm{NO}_{2}{ }^{+} / \mathrm{O}_{2}$ and $\mathrm{CH}_{3} \mathrm{NO}_{2}{ }^{+} \cdot / \mathrm{He}$ in the range $190-570 \mathrm{~nm}$, respectively. The $\mathrm{CH}_{3} \mathrm{NO}_{2}^{+} \cdot / \mathrm{O}_{2}$ CIE spectra exhibit three narrow atomic emission peaks of $\mathrm{C}\left(3 \mathrm{~s}{ }^{1} \mathrm{P}^{0} \rightarrow 1 \mathrm{p}{ }^{1} \mathrm{D}\right), \mathrm{H} \cdot{ }_{\beta}$ $(n=4 \rightarrow n 2)$ and $\mathrm{H}_{\lambda}(n=5 \rightarrow n 2)$ [17], as well as a broad emission band ranging from 190 to $310 \mathrm{~nm}$ (i.e., well within the range of the SR band). In contrast, the CIE spectrum of $\mathrm{CH}_{3} \mathrm{NO}_{2}{ }^{+} \cdot / \mathrm{He}$ collisions exhibits no obvious emissions in this spectral range. Although the CIE spectrum of $\mathrm{CH}_{3} \mathrm{NO}_{2}{ }^{+} \cdot \mathrm{O}_{2}$ indicates that large amounts of excited $\mathrm{C}$ and $\mathrm{H}$. were produced during the collision, the ion fragment at $m / z 49$ (corresponding to the loss of $\mathrm{C}$ ) is not shown in the $\mathrm{O}_{2}$ CID mass spectrum. The $m / z 60$ (loss of H.) peak has a similar intensity in the $\mathrm{He}$ and $\mathrm{O}_{2}$ CID mass spectra. In 1987, Mclafferty et al. [18] reported that the efficiency of the CID process was related to the ionization potential of the target gas, and Cooks' group [19] showed that the CID efficiency is greater for $\mathrm{He}$ targets because losses due to scattering and neutralization are reduced. Accordingly, the significant amounts of excited $\mathrm{C}$ and $\mathrm{H}$. that are only seen in the CIE spectrum of $\mathrm{CH}_{3} \mathrm{NO}_{2}{ }^{+} / \mathrm{O}_{2}$ could be produced by dissociative charge transfer rather than CID.

In order to enhance the signal-to-noise ratio, target gas pressures were increased to produce a $40 \%$ reduction in the beam. The resulting CIE spectra are shown in Figure 3b. In the CIE spectrum of $\mathrm{CH}_{3} \mathrm{NO}_{2}{ }^{+} / \mathrm{O}_{2}$, the peak at $314 \mathrm{~nm}$ was assigned to atomic emission from $\mathrm{O}^{+} \cdot\left(4 \mathrm{~s}^{4} \mathrm{P}^{0} \rightarrow 3 \mathrm{p}^{4} \mathrm{D}^{0}\right)$ [17], again confirming that charge transfer reactions occur during ion- $\mathrm{O}_{2}$ collisions. Although the strength of the broad peak increased, it was still too weak to be identified. The CIE spectrum of $\mathrm{CH}_{3} \mathrm{NO}_{2}{ }^{+} / \mathrm{He}$ shows no obvious emissions, indicating that the unidentified broad peak could come from the target $\mathrm{O}_{2}$.

The simpler $\mathrm{N}_{2}{ }^{+}$. $/$target gas system was also studied. Figure 4 shows the CIE spectra obtained from $\mathrm{N}_{2}{ }^{+} / \mathrm{O}_{2}$ and $\mathrm{N}_{2}{ }^{+} \cdot / \mathrm{He}$ collisions in the range $190-570 \mathrm{~nm}$. Both spectra show molecular emission from $\mathrm{N}_{2}{ }^{+}$and $\mathrm{N}_{2}$ [20-22]. The broad feature in this region is now more intense, but again appears only in the $\mathrm{N}_{2}{ }^{+} / \mathrm{O}_{2}$ CIE spectrum, while $\mathrm{N}_{2}{ }^{+} \cdot \mathrm{He}$ collisions give only atomic emission from helium. Figure $5 \mathrm{a}$ shows a higher-resolution CIE spectrum for which the slits were narrowed from 3 to $1 \mathrm{~mm}$ and the accumulation time was increased from 2 to $8 \mathrm{~h}$. The unknown broad peak showed obvious vibrational structure which enabled it to be identified. The best match to the experimental data was not found to be the $\mathrm{O}_{2}$ SR bands, but rather $\mathrm{A}^{2} \Pi_{\mathrm{u}} \rightarrow \mathrm{X}^{2} \Pi_{\mathrm{g}} \mathrm{O}_{2}{ }^{+}$. ion emission, which falls in the same energy window (Figure 2). The $\mathrm{O}_{2}{ }^{+} \cdot \mathrm{A} \rightarrow \mathrm{X}$ emissions have obvious band heads and they are red-degraded and double-headed. The wavelengths of the $\mathrm{A} \rightarrow \mathrm{X}$ bands range from 194 to $653 \mathrm{~nm}$, overlapping heavily with the SR band and thus making emission identification difficult. The vertical lines in Figure 5a show the $\mathrm{O}_{2}{ }^{+} \mathrm{A} \rightarrow \mathrm{X}$ emission bands reported in the literature [16], and agreement with the experimental data is excellent. However, the characteristic double heads of the bands were not observed, due to low resolution. Figure $5 \mathrm{~b}$ shows the CIE spectrum with the slit width reduced to $0.5 \mathrm{~mm}$. The spectrum shows that though the peak intensity weakens, we now observe the characteristic splitting of the $\mathrm{A} \rightarrow \mathrm{X} \mathrm{O}_{2}{ }^{+}$emission bands, confirming the existence of a significant amount of $\mathrm{O}_{2}{ }^{+}$from charge transfer reactions. A full list of experimentally observed band heads and the reported $\mathrm{O}_{2}{ }^{+} \mathrm{A} \rightarrow \mathrm{X}$ emission bands is available in the Electronic Supplementary Material.

Based on the above observation of the $\mathrm{O}_{2}$ excited states produced, it is proposed that there are two possibilities: one is that there is no SR band formed in the collision; the other is that the $\mathrm{A} \rightarrow \mathrm{X} \mathrm{O}_{2}{ }^{+}$. emission produced from the charge transfer reaction between $\mathrm{N}_{2}^{+}$and $\mathrm{O}_{2}$ is so intense that it masks the SR

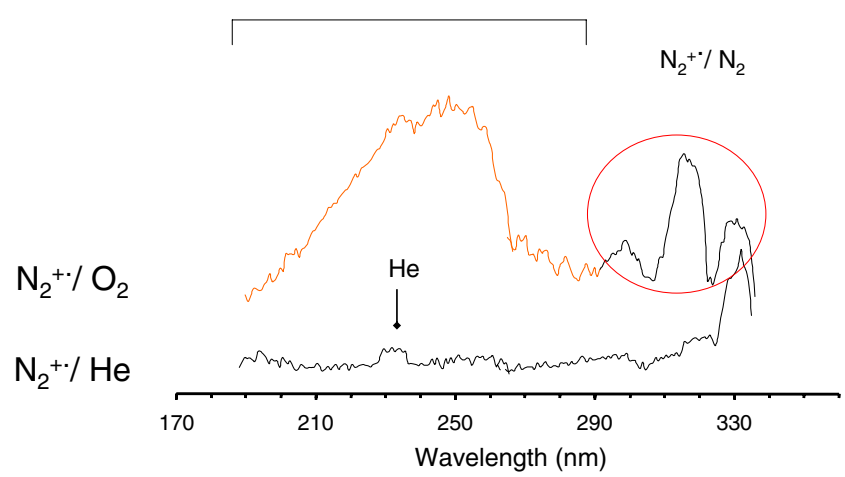

Figure 4. CIE spectra of $\mathrm{N}_{2}{ }^{+} / \mathrm{O}_{2}$ and $\mathrm{N}_{2}{ }^{+} / \mathrm{He}: 40 \%$ beam reduction, slit width $3 \mathrm{~mm}$, accumulation time $2 \mathrm{~h}$. The bands that appear above $290 \mathrm{~nm}$ (marked by a circle) were identified as the emissions from $\mathrm{N}_{2}{ }^{+\cdot}$ and $\mathrm{N}_{2}$ 
(a)

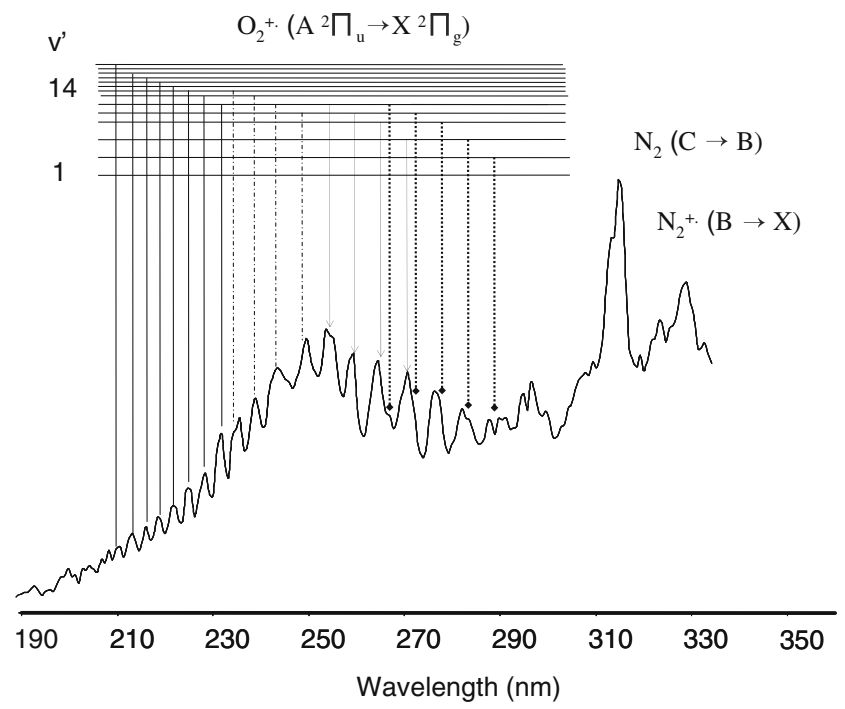

(b)

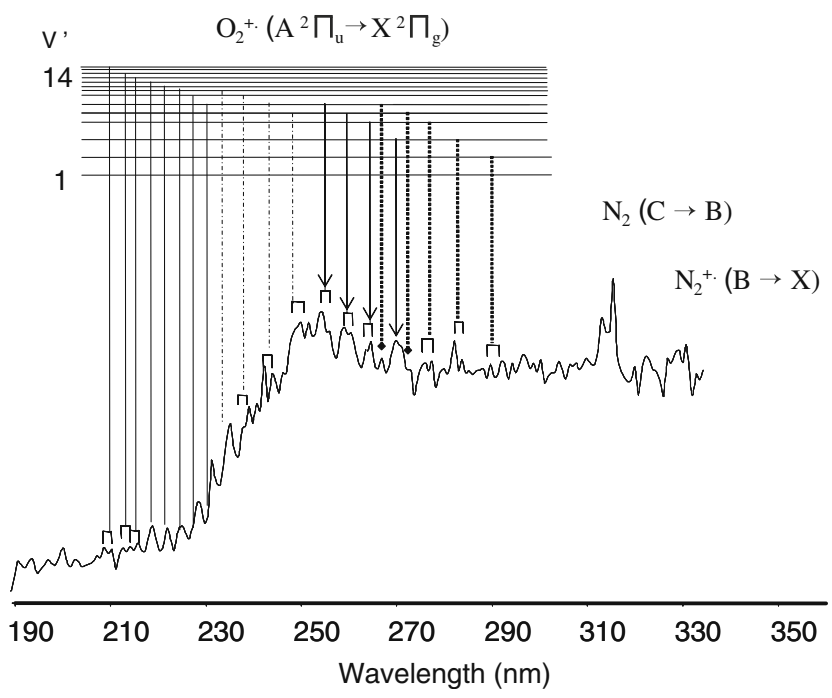

Figure 5. (a) $\mathrm{CIE}$ spectrum of $\mathrm{N}_{2}^{+} / \mathrm{O}_{2}: 40 \%$ beam reduction, accumulation time $8 \mathrm{~h}$, slit width $1 \mathrm{~mm}$. (b) CIE spectrum of $\mathrm{N}_{2}{ }^{+} / \mathrm{O}_{2}: 40 \%$ beam reduction, accumulation time $8 \mathrm{~h}$, slit width $0.5 \mathrm{~mm}$. Superimposed on the spectrum are the $A$ ${ }^{2} \Pi_{\mathrm{u}} \rightarrow \mathrm{X}^{2} \Pi_{\mathrm{g}} \mathrm{O}_{2}{ }^{+.}$emission bands reported in the literature [15]

emission. To exclude the latter case, $\mathrm{CH}_{3}{ }^{+}$was chosen as a projectile ion (ionization energy $=9.84 \mathrm{eV}$; compare to $12.07 \mathrm{eV}$ for $\mathrm{O}_{2}$ ) [23], so that the charge transfer reaction producing the $\mathrm{O}_{2}{ }^{+}$. ion is not thermochemically favored (a full table of all IE values for the compounds studied herein can be found in the Electronic Supplementary Material). Figure 6 shows the CIE spectra for $\mathrm{CH}_{3}{ }^{+} / \mathrm{O}_{2}$ collisions and the $\mathrm{N}_{2}{ }^{+} / \mathrm{O}_{2}$ system. Of course, the $\mathrm{N}_{2}{ }^{+}$and $\mathrm{N}_{2}$ emissions were not observed, and two atomic emissions from C. $\left(3 \mathrm{~s}^{1} \mathrm{P}^{0} \rightarrow 1 \mathrm{p}{ }^{1} \mathrm{D}\right)$ and $\mathrm{O}^{+}$. $\left(4 \mathrm{~d}^{4} \mathrm{P} \rightarrow 3 \mathrm{p}^{4} \mathrm{~S}^{0}\right.$ ) were found. Band emission is also present and, compared with that from the $\mathrm{N}_{2}^{+} \cdot \mathrm{O}_{2}$ system, it is less intense and shows no well-resolved band heads. The accumulation time was increased from 8 to $10 \mathrm{~h}$, and the resulting spectrum is shown in Figure. $6 \mathrm{~b}$. The vertical lines
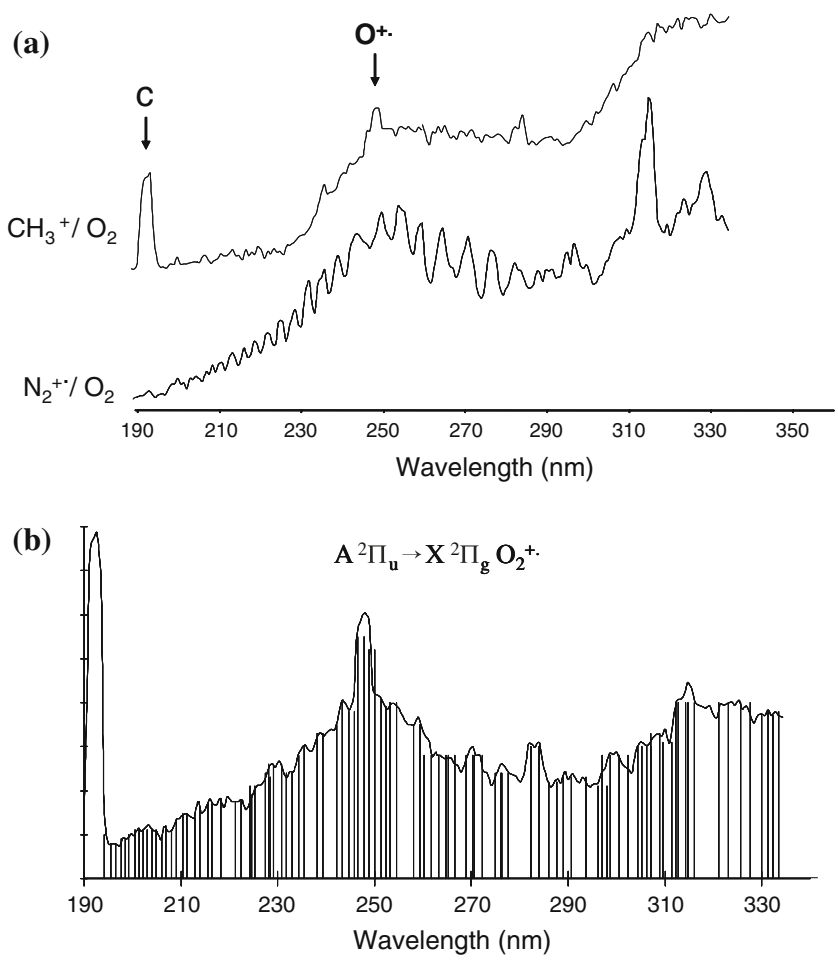

Figure 6. (a) ClE spectra of $\mathrm{N}_{2}{ }^{+} \cdot \mathrm{O}_{2}$ and $\mathrm{CH}_{3}{ }^{+} / \mathrm{O}_{2}: 40 \%$ beam reduction, accumulation time $8 \mathrm{~h}$, slit width $1 \mathrm{~mm}$. (b) $\mathrm{CIE}$ spectrum of $\mathrm{CH}_{3}{ }^{+} / \mathrm{O}_{2}: 40 \%$ beam reduction, accumulation time $10 \mathrm{~h}$, slit width $0.5 \mathrm{~mm}$. Superimposed on the spectrum are the $\mathrm{A}^{2} \Pi_{\mathrm{u}} \rightarrow \mathrm{X}^{2} \Pi_{\mathrm{g}} \mathrm{O}_{2}{ }^{+}$emission bands reported in the literature [15]

show the wavelengths of $\mathrm{O}_{2}^{+} \mathrm{A} \rightarrow \mathrm{X}$ emission. The band emission agrees with $\mathrm{A} \rightarrow \mathrm{X} \mathrm{O}_{2}{ }^{+}$emission. When compared with the SR bands in the literature - as shown in Figure 7-it is clear that there are several peaks (marked by arrows) that do not agree with SR band values.

Above all, there is a lack of strong evidence for the formation of a significant amount of the $\mathrm{B}$ state of $\mathrm{O}_{2}$. However, the $\mathrm{A} \rightarrow \mathrm{X} \mathrm{O}_{2}{ }^{+}$. emission bands and dissociative charge-transfer product emissions were consistently

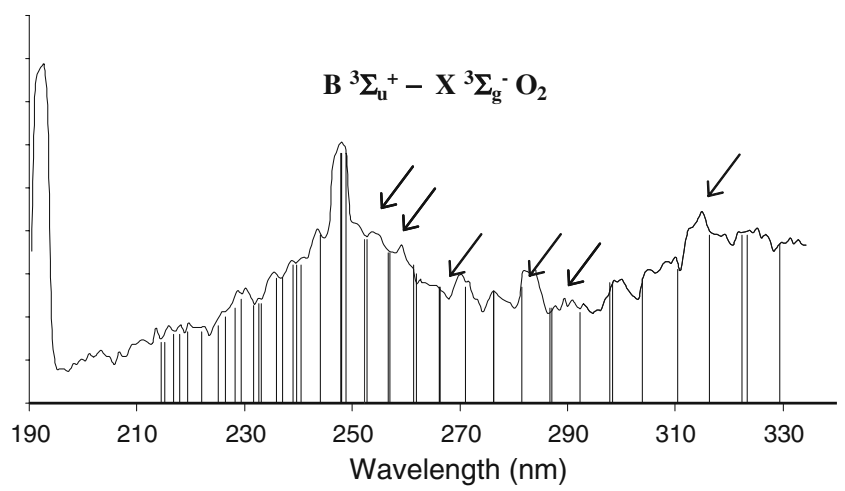

Figure 7. $\mathrm{CIE}$ spectrum of $\mathrm{CH}_{3}{ }^{+} / \mathrm{O}_{2}: 40 \%$ beam reduction, accumulation time $10 \mathrm{hrs}$, slit width $0.5 \mathrm{~mm}$. Superimposed on the spectrum are the Schumann-Runge emission bands reported in the literature [15] 
observed, even when charge transfer was thermochemically unfavorable, indicating that a considerable amount of the A state of $\mathrm{O}_{2}^{+}$can be generated during ion- $\mathrm{O}_{2}$ collisions. Combining this with the fact that the energy difference between the $\mathrm{A}$ and $\mathrm{X} \mathrm{O}_{2}{ }^{+} \cdot$ states is close to that between the $\mathrm{B}$ and $\mathrm{X} \mathrm{O}_{2}$ states [16], a second potential mechanism can be put forward to rationalize the enhancing effect of $\mathrm{O}_{2}$ : during ion- $\mathrm{O}_{2}$ collisions, electron transfer in the collision complex generates a significant amount of the $\mathrm{O}_{2}{ }^{+}$A state. During the separation of the collision complex, some of the $\mathrm{O}_{2}^{+}$ ions remain in the A state (collisional charge transfer) and emit, while others transfer charge back to the projectile, reforming $\mathrm{O}_{2}$ in its ground state and leaving the $\mathrm{A} \rightarrow \mathrm{X}$ energy quantum in the projectile ion, thus allowing it to undergo $\mathrm{O}_{2}$-enhanced dissociation. Charge-transfer reactions occur on the femtosecond time-scale. For example, the time taken for Ar to exchange charge with Ru has been calculated to be 1-2 fs [24]. The lifetime of the collision complex can be estimated from the collision diameter of the gas particles and the velocity of the projectile ion (with a kinetic energy of $8 \mathrm{keV}$ ) to be $\sim 2 \mathrm{fs}$ for $\mathrm{N}_{2}{ }^{+} \cdot \mathrm{O}_{2}$, which is similar to the time taken for charge transfer.

\section{Conclusions}

Strong $\mathrm{O}_{2}{ }^{+} \mathrm{A} \rightarrow \mathrm{X}$ emission was observed in $\mathrm{N}_{2}{ }^{+} / \mathrm{O}_{2} \mathrm{CIE}$ experiments due to the charge-transfer reaction between $\mathrm{N}_{2}{ }^{+}$ and $\mathrm{O}_{2}$. This emission band is also observed from $\mathrm{CH}_{3}{ }^{+} / \mathrm{O}_{2}$ collisions, even though charge transfer is thermochemically unfavorable in this case. It is postulated that the observed enhancement generated by $\mathrm{O}_{2}$ for certain dissociation channels in $\mathrm{O}_{2}$ CID experiments may result from the participation of this charge-transfer band, rather than the participation of the $\mathrm{O}_{2}$ Schumann-Runge bands (as previously hypothesized).

\section{Acknowledgments}

PMM thanks the Natural Sciences and Engineering Research Council of Canada for continuing financial support.

\section{References}

1. Mcluckey, S.A.: Principles of collisional activation in analytical mass spectrometry. J. Am. Soc. Mass Spectrom. 3, 599-614 (1992)

2. Mayer, P.M., Poon, C.: The mechanisms of collision activation of ions in mass spectrometry. Mass Spectrom. Rev. 28(3), 608-639 (2009)

3. Holmes, J.L., Aubry, C., Mayer, P.M.: Assigning structures to ions in mass spectrometry. CRC, Boca Raton (2007)
4. Flammang, R., Gallez, L., VanHaverbeke, Y., Wong, M.W., Wentrup, C.: An unexpected effect of the nature of the collision gas in collisional activation mass spectrometry. Rapid Commun. Mass Spectrom. 10(2), 232-234 (1996)

5. Gerbaux, P., Barbieux-Flammang, M., Van Haverbeke, Y., Flammang, R.: Characterization of ionized heterocyclic carbenes by ion-molecule reactions. Rapid Commun. Mass Spectrom. 13(17), 1707-1711 (1999)

6. Flammang, R., Gerbaux, P., Wong, M.W.: Identification of singlet and triplet CNOS+cations in the gas phase. Chem. Phys. Lett. 300(1), 183188 (1999)

7. Flammang, R., Henrotte, V., Gerbaux, P., Nguyen, M.T.: Collisional interaction of ionized pyridine $\mathrm{N}$-oxides with various targets in a new hybrid mass spectrometer. Eur. Mass Spectrom. 6(1), 3-9 (2000)

8. Gerbaux, P., Sciamanna, V., Flammang, R., Nguyen, M.T.: Highenergy collisional activation of the molecular ions of thiophene-2-one with different target gases. J Mass Spectrom. 36(1), 97-101 (2001)

9. Aubry, C., Holmes, J.L.: A Butyl cations and their gas-phase dissociation chemistry: uniting experiments with theory. J Phys. Chem. 102(32), 64416447 (1998)

10. Aubry, C., Holmes, J.L.: The behavior of oxygen as a collision-induced dissociation target gas. J Am. Soc. Mass Spectrom. 12(1), 23-29 (2000)

11. Holmes, J.L.: Assigning structures to ions in the gas phase. Org. Mass Spectrom. 20(3), 169-183 (1985)

12. Burgers, P.C., Holmes, J.L., Szulejko, J.E., Mommers, A.A., Terlouw, J.K.: The gas phase ion chemistry of the acetyl cation and isomeric $\left[\mathrm{C}_{2} \mathrm{H}_{3} \mathrm{O}\right]^{+}$ions. On the structure of the $\left[\mathrm{C}_{2} \mathrm{H}_{3} \mathrm{O}\right]^{+}$daughter ions generated from the enol of acetone radical cation. Org. Mass Spectrom. 18 (6), 254-262 (1983)

13. Holmes, J.L., Mommers, A.A., Terlouw, J.K., Hop, C.E.C.A.: The mass spectrometry of neutral species produced from mass-selected ions by collision and by charge exchange. Experiments with tandem collision gas cells. Int. J. Mass Spectrom. Ion Processes. 68(3), 249-64 (1986)

14. Holmes, J.L., Mayer, P.M., Mommers, A.A.: Photon emissions from $\mathrm{N}_{2}{ }^{++}$ion beam-target gas collisions in a modified commercial sector mass spectrometer. Int. J. Mass Spectrom. Ion Process. 135(2-3), 21328 (1994)

15. Poon, C., Mayer, P.M.: Experimental evidence for the curve crossing mechanism for collisional excitation in $\mathrm{keVN}_{2}{ }^{+} \cdot \mathrm{He}$ collisions by emission spectroscopy. J. Phys. Chem. A. 111(5), 777-782 (2007)

16. Krupenie, P.H.: Spectrum of molecular oxygen. J. Phys. Chem. Ref. Data. 1(2), 423-534 (1972)

17. Bashkin, S., Stoner Jr., J.O.: Atomic energy levels and Grotnan diagrams. North Holland Press, New York (1975)

18. Kim, M.S., McLafferty, F.W.: Collisional activation and metastable ion characteristics. 59. Efficiency of collisional activation of gaseous organic ions. J. Am. Chem. Soc. 100(11), 3279-3282 (1978)

19. Laramee, J.A., Cameron, D., Cooks, R.G.: Collision-induced dissociation mass spectrometry: target gas effects upon scattering and charge exchange. J. Am. Chem. Soc. 103(1), 12-17 (1981)

20. Bennett, R.G., Dalby, F.W.: Experimental determination of the oscillator strength of the first negative bands of $\mathrm{N}_{2}^{+}$. J. Chem. Phys. 31, 434-41 (1959)

21. Hesser, J.E., Dressler, K.J.: Radiative lifetimes of ultraviolet molecular transitions. Chem. Phys. 45(8), 3149-3150 (1966)

22. Lofthus, A., Krupenie, P.H.: The spectrum of molecular nitrogen. $J$. Phys. Chem. Ref. Data. 6(1), 113-307 (1977)

23. Linstrom, P.J., Mallard, W.G. (Eds.): NIST Standard Reference Database, number 69. National Institute of Standards and Technology, Gaithersburg (2010) (http://webbook.nist.gov, retrieved 2 June 2010)

24. Wurth, W.: Femtosecond dynamics of adsorbate charge transfer processes. Appl. Phys. A 65(6), 597-601 (1997) 